\title{
REVISTA
ESMAT
}

8

\section{A CAPACIDADE JURÍDICO-POSTULATÓRIA DO INDIVÍDUO EM ÂMBITO INTERNACIONAL DE PROTEÇÃO E DEFESA DOS DIREITOS HUMANOS}

Wellington Magalhães

Membro do Comitê Técnico de Formação e Pesquisa da Escola Nacional de Formação e Aperfeiçoamento de Magistrados (ENFAM). Tutor de ensino à distância do Centro de Aperfeiçoamento e Formação de Servidores do Poder Judiciário (CEAJUD/CNJ). Professor e coordenador de cursos da Escola Superior da Magistratura do Tocantins (ESMAT). Mestre em Direito Constitucional pela Universidade de Coimbra, Portugal (FDUC).

\section{RESUMO}

O presente trabalho pretende abordar a capacidade postulatória do indivíduo em âmbito internacional de proteção e defesa dos direitos humanos. Tendo em vista o pioneirismo dos sistemas europeu e americano de direitos humanos, o trabalho também faz um paralelo entre esses dois sistemas.

PALAVRAS-CHAVE: Direitos Humanos. Proteção Internacional. Capacidade Postulatória. Convenção Americana de Direitos Humanos. Convenção Europeia de Direitos Humanos.

\section{ABSTRACT}

This paper deals with the postulatória capacity of the individual at the international level of protection and defense of human rights. Because of the pioneering of European and American human rights systems, work makes a distinction between these two systems.

KEYWORDS: Human Rights. International protection. Postulatória capacity. American Convention on Human Rights. European Convention on Human Rights. 


\section{INTRODUÇÃO}

A revelação de que todos os seres humanos merecem respeito não é um dado da modernidade, e sim o resultado de longo percurso histórico de afirmação e defesa da dignidade humana contra a violência, a exploração e a miséria. Daí o porquê da íntima ligação entre os direitos do homem e a dignidade humana. Assim, estudar os direitos humanos é, antes de tudo, compreender a ideia central de dignidade humana, cujas explicações centrais podem ser colhidas tanto na religião quanto na filosofia.

Ademais, não obstante a noção de direitos inerentes à pessoa humana encontrar expressão, ao longo da história, em regiões e épocas distintas, a formação jurídica dessa noção no plano internacional é recente, especialmente a partir da Declaração Universal dos Direitos Humanos, de 1948. As raízes do que hoje se entende por proteção internacional dos direitos humanos não é senão o resultado de longos movimentos sociais e políticos, correntes filosóficas e jurídicas, que a par das atrocidades testemunhadas ao longo dos séculos, traduzem na atualidade a universalidade e a indivisibilidade dos direitos humanos.

Nesse contexto, o processo de generalização dos direitos humanos pode ser analisado em dois planos, quais sejam, o "normativo" e o "operacional". No que toca ao primeiro plano, limitar-se-á a ressaltar a importância da Declaração Universal dos Direitos do Homem ( 1948 ) para a multiplicação de instrumentos jurídicos internacionais de proteção dos direitos humanos, e. g., Pacto Internacional de Direitos Civis e Políticos, Pacto Internacional de Direitos Econômicos, Sociais e Culturais, Convenção Europeia de Direitos do Homem, Convenção Americana de Direitos Humanos etc.

Neste trabalho, abordar-se-ão os dois principais sistemas regionais de proteção e defesa dos direitos humanos: o "europeu" e o "interamericano". A escolha por estes sistemas não é aleatória, pois se funda no "pioneirismo" que Ihes são próprios, nomeadamente no que tange ao europeu, cujos instrumentos de coerção muitas das vezes acabam por serem mais eficazes do que o interamericano. Contudo, o foco não é o de avaliar os critérios de eficiência entre os dois sistemas, tampouco traçar um paralelo entre os procedimentos adotados por ambos. A proposta é a de analisar o fenômeno da generalização dos instrumentos de proteção e defesa dos direitos humanos, designadamente a "capacidade jurídico-processual dos indivíduos" nos "órgãos de jurisdição internacional" contemplados pelas Convenções Europeia e Americana de Direitos Humanos. 


\section{AAFIRMAÇÃO HISTÓRICA DOS DIREITOS HUMANOS}

\section{Compreender o "ser" e a noção de sua dignidade humana}

Segundo Boaventura, os direitos humanos são parte integrante do projeto da modernindade. Projeto este que é a um só tempo revolucionário e ambicioso (SANTOS, 1989). Todavia, a revelação de que todos os seres humanos merecem respeito não é dado da modernidade, e sim o resultado de um longo percurso histórico de afirmação e defesa da dignidade humana contra a violência, a exploração e a miséria (COMPARATO, 2007). Daí o porquê da íntima ligação entre os direitos do homem e a dignidade humana. Assim, estudar os direitos humanos é antes de tudo compreender a ideia central de dignidade humana, cujas explicações centrais podem ser colhidas tanto na religião quanto na filosofia.

A justificativa religiosa da preeminência do ser humano no mundo surgiu com a afirmação da fé monoteísta (COMPARATO, 2007). Segundo o relato bíblico da Criação, o mundo não surge pronto e acabado das mãos do Criador. Pelo contrário, de acordo com o Livro de Gêneses, as criaturas vão se adicionando, umas às outras, como etapas de um amplo projeto da Divindade. O homem e a mulher só entram em cena na última fase da obra divina, quando todos os demais seres terrestres já haviam sido criados. Também conforme as escrituras bíblicas, o homem foi criado à semelhança de Deus; porém tirado da terra, isto é, situado entre o Céu e a Terra, como um ser a um só tempo espiritual e terreno (COMPARATO, 2007).

Fábio Konder Comparato relata que "a fé monoteísta alcança em Israel sua expressão mais pura no século VI a. C. com o Dêutero-Isaías, o autor anônimo dos capítulos 40 a 55 do Livro de Isaías" (COMPARATO, 2007, p. I0). Para o citado autor, "o cristianismo foi quem levou às últimas consequências o ensinamento ecumênico de Isaías, envolvendo-o na exigência de amor universal" (COMPARATO, 2007, P. I I). Na tradição bíblica, segundo o Livro de João, versículo 12, Deus é o modelo de pessoa para todos os seres humanos; e Jesus de Nazaré, a concretização perfeita do modelo ético de pessoa. Assim, é nesse contexto que São Paulo levou o universalismo do evangelho às últimas consequências, ao afirmar que, diante da comum filiação divina, já não há nem judeu nem grego, nem escravo nem livre, nem homem nem mulher (Gálatas 3, v. 26-29). Em suma, a compreensão da dignidade humana, no plano divino, parte da constatação de que a igualdade entre os seres humanos, apesar de suas múltiplas diferenças individuais e grupais, não é senão a verdade de um Deus que é pai, filho e espírito santo. 
No campo das explicações filosóficas, impende salientar que no século $V$ a.C., tanto na Ásia quanto na Grécia, a filosofia nasce em substituição, pela primeira vez na história, do saber mitológico da tradição pelo saber lógico da razão. Segundo Comparato, "a tragédia grega, muitos séculos antes da psicanálise, representou a primeira grande introspecção nos subterrâneos da alma humana, povoados de paixões, sentimentos e emoções, de caráter irracional e incontrolável. O homem aparece, aos seus próprios olhos, como um problema, ele é em si mesmo um problema" (COMPARATO, 2007, p. 10), i. e., um obstáculo à compreensão, uma dificuldade proposta à razão humana. É um dar-se conta de si mesmo numa perspectiva desconhecida e instigante. $\bigcirc$ ser humano é o laboratório de si.

Ainda no campo da filosofia, importante foram os contributos do pensamento estóico, que se baseava nalgumas ideias centrais, como, por exemplo, a unidade moral do ser humano e sua dignidade enquanto espécie humana (JUSTO, 2005). Segundo o estoicismo, a dignidade do homem decorria de sua filiação para com Zeus, razão por que possuía direitos inatos e iguais em todas as partes do mundo, não obstante as diferenças individuais e grupais. São Tomás de Aquino, com arrimo na definição de Boécio (COMPARATO, 2007), também contribuiu significativamente para o conceito de pessoa, que para ele seria um composto de substâncias espiritual e corporal (HAARSCHER, 1993), pelo que se pode, nesse particular, afirmar a aproximação entre as compreensões filosóficas e religiosas numa só tentativa de explicar a natureza do ser humano, seu conceito e sua essencial dignidade.

Outro grande momento de elaboraçao filosófica do conceito de pessoa identifica-se com a obra de Kant, para quem todo homem tem dignidade, e não um preço. Segundo a filosofia kantiana, "a humanidade como espécie, e cada ser humano em sua individualidade, é propriamente insubstituível: não tem equivalente, não pode ser trocado por coisa alguma" (COMPARATO, 2007, p. 20). Em suma, abordar a humanidade como um fim em si indica o dever de defender, tanto quanto possível, o fim de outrem, nomeadamente porque a dignidade humana encontra-se assentada num ideal comum, v. g., num conjunto univeral e indivisível de valores e preceitos básicos inerentes ao indivíduo antes mesmo de qualquer organização política, social ou jurídica (WARBURTON , 2007).

Mas a compreensão da pessoa ou de sua inerente dignidade não repousa apenas nas explicações religiosas e filosóficas. Confirmando a visão da filosofia estóica, segundo a qual a essência da pessoa não se confunde com a função ou papel que cada indivíduo exerce na vida, Comparato relata que a descoberta da 
A CAPACIDADE JURÍDICO-POSTULATÓRIA DO INDIVÍDUO EM ÂMBITO INTERNACIONAL DE PROTEÇÃO E DEFESA DOS DIREITOS HUMANOS

estrutura do ADN, em 1953, revelou que cada um de nós carrega um patrimônio próprio e, salvo no caso de gêmeos homozigóticos, um patrimônio genético único. Ou seja, "o caráter único e insubstituível de cada ser humano, portador de um valor próprio, veio demonstrar que a dignidade da pessoa existe singularmente em todo indivídiduo, logo, nenhuma justificativa de utilidade pública ou reprovação social pode legitimar a pena de morte, cruéis ou degradantes" (COMPARATO, 2007, p. 3 I). Ou seja, ainda que a substância da dignidade humana não esteja claramente definida, devemos reconhecer o princípio como princípio fundamental da bioética. Seja qual for a nacionalidade, a raça ou a religião, ninguém nega o valor fundamental da dignidade dos seres vivos. Cada pessoa tem a sua dignidade própria" (IDA, 2006). Assim, somandose às compreensões religiosas e filosóficas, também a constatação de que todos somos possuidores de um patrimônio genético próprio somente «reafirma» a prevalência dos valores e preceitos básicos que circunscrevem o âmbito de proteção da pessoa e de sua inerente dignidade.

\section{A afirmação dos direitos humanos e as declarações de direitos}

Não obstante a noção de direitos inerentes à pessoa humana encontrar expressão, ao longo da história, em regiões e épocas distintas, a formação jurídica dessa noção no plano internacional é recente, especialmente a partir da Declaração Universal dos Direitos Humanos, de 1948. Mas como relata Trindade, as raízes do que hoje se entende por proteção internacional dos direitos humanos não é senão o resultado de longos movimentos sociais e políticos, correntes filosóficas e jurídicas, que, a par das atrocidades testemunhadas ao longo dos séculos, traduzem na atualidade a universalidade e a indivisibilidade dos direitos humanos (TRINDADE, 2003).

Com efeito, a eclosão da consciência histórica dos direitos humanos só se deu após um longo período preparatório, centrado em torno da limitação do poder político. Em sua obra A Afirmação Histórica dos Direitos Humanos (COMPARATO, 2007) faz um relato minucioso desse fenômeno ligado à limitação do poder político-estatal, contudo, por questões de delimitação temática adiante, passar-se-á aos fatos históricos que mais recentemente se vinculam ao progressivo fortalecimento dos direitos do homem; ou seja, aos fatos a partir dos quais efetivamente se pode tratar de um «autônomo» instituto denominado direitos humanos (TRINDADE, 2003).

Inicialmente, tem-se que "a Declaração de Direitos Norte-Americana, juntamente com a Declaração Francesa, de 1789, representam a emancipação 
histórica do indivíduo perante os grupos sociais aos quais ele sempre se submeteu: a família, o clã, o estamento, as organizações religiosas" (MIRANDA, 20 I2). No entanto, como adverte Comparato, "é preciso reconhecer que o terreno, nesse campo, fora preparado mais de dois séculos antes; de um lado pela reforma protestante, que enfatizou a importância decisiva da consciência individual em matéria moral e religião; de outro lado, pela cultura da personalidade de exceção, do herói que forja sozinho o seu próprio destino e os destinos do seu povo, como se viu sobretudo na Itália renascentista" (COMPARATO, 2007, p. 53).

Nas lições de Haarscher, os direitos humanos consagrados nas declarações norte-americana e francesa nada mais são senão o produto de uma filosofia individualista e liberal. Ou seja, o indivíduo (pessoa!), com os seus direitos, constitui o fim da associação política, o que religa a concepção dos direitos do homem à ideia de um poder fundamentado no contrato social. Para o mesmo autor, esse contratualismo que se desenvolveu na época moderna possui em geral quatro características mais importantes: «o estado de natureza, o direito natural, o contrato propriamente dito, e o racionalismo» (HAARSCHER, I993, p. 16).

Ainda segundo Haarscher, a ideia de um estado de natureza parte de uma concepção de que naturalmente os homens são livres e iguais. São livres porque ninguém exerce autoridade natural sobre outrem, ou porque cada um é, no estado de natureza, o seu próprio dono (HAARSCHER, 1993). E se assim o é, o poder político ou estadual só existe se houve concordância dos indivíduos, i. e., todo poder emana da renúncia que cada indivíduo faz de parcela de sua autonomia, de modo que o ideal comum de bem viver e se defender das agressões externas pudesse ser alcançado. Está-se aqui a falar do contrato social que jamais existiu, mas cujas consequencias são as mesmas, dado que vivemos a autoridade política como se só um contrato garantindo o respeito pelos direitos do homem a ela nos ligasse (HAARSCHER, 1993).

A propósito do racionalismo, com respaldo em Locke, tem-se que todos os direitos naturais são reconhecidos por evidência, ou seja, por todo o indivíduo capaz de utilizar a sua razão, característica esta que o distingue de todas as demais espécies de seres vivos (LOCKE Apud HAARSCHER, 1993). Em outras palavras, a "universalidade do direito natural deriva da presença da faculdade racional em todo o homem", pelo que vale para todo o indivíduo e impõe-se como uma verdade "às luzes da nossa Razão" (GROTIUS Apud HAARSCHER, 1993, p. 26). Destarte, até aqui se pode concluir que os direitos humanos são inerentes ao ser humano, e como tais são anteriores a todas as formas de 
organização política. Nesse sentido, não é demais afirmar que, apesar das justas distinções entre as declarações de direitos norte-americana e francesa, ambas representam a primeira condensação dos valores e preceitos básicos da proteção do ser humano contra toda espécie de violência. Contudo, somente com a Declaração Universal dos Direitos Humanos pode-se afirmar ter, de fato, havido universalização dos direitos humanos. Com efeito, a Declaração Universal, de 1948, afigura-se como a fonte inspiradora, um ponto de irradiação e convergência dos instrumentos sobre direitos humanos em âmbito tanto global quanto regional (TRINDADE, 2003). Como afirmou López, "al intentar realizar um repasso histórico al proceso de creación de los derechos humanos, el año 1948 se convierte em uma referencia casi obligada, por la trascendencia posterior que tuvo la aprobación de la Declaración Universal em el seno de la Asamblea General de Naciones Unidas, el 10 de diciembre de aquel año" (LÓPEZ, 2004, p. 22).

Para Cançado Trindade, após a Declaração Universal dos Direitos Humanos, o mundo assistiu a uma "generalização e expansão da proteção internacional dos direitos humanos", o que, na sua opinião, "em muito ultrapassou o que poderiam originariamente antever seus redatores" (TRINDADE, 2003, p. 69). O processo de generalização dos direitos humanos pode ser analisado em dois planos, quais sejam, o «normativo» e o «operacional». No que toca ao primeiro plano, limitar-se-á a ressaltar a importância da Declaração Universal dos Direitos do Humanos para a "multiplicação" de instrumentos jurídicos internacionais de proteção dos direitos humanos, e. g., Pacto Internacional de Direitos Civis e Políticos, Pacto Internacional de Direitos Econômicos, Sociais e Culturais, Convenção Europeia de Direitos do Homem, Convenção Americana de Direitos Humanos etc. Ou seja, a partir da Declaração Universal, de 1948, inúmeros outros instrumentos de proteção dos direitos humanos foram se consolidando de modo global e regional (TRINDADE, 2003).

Quanto ao plano «operacional», e aqui se adentra no tema de principal abordagem deste trabalho, o fenômeno de maior relevância é sem dúvida a afirmação da capacidade jurídica postulatória da pessoa humana (MIRANDA, 2012), v. g., capacidade jurídica internacional do ser humano (TRINDADE, 2003), cujo enquadramento teórico se diferiu para o próximo tópico deste trabalho, donde se pretende enfrentá-lo sob a ótica operacional dos sistemas europeu e interamericanos de proteção e defesa dos direitos humanos. 


\section{A CAPACIDADE JURÍDICO-POSTULATÓRIA DO INDIVÍDUO EM ÂMBITO INTERNACIONAL DE PROTEÇÃO E DEFESA DOS DIREITOS HUMANOS}

\section{A nova ordem internacional}

É inegável que a Declaração dos Direitos do Homem inaugurou uma nova ordem internacional focada nos valores inerentes à dignidade humana. $\bigcirc$ direito internacional que antes se fundava nas premissas do Tratado de Westphalia, a partir de então passaria por um longo processo de humanização. A Declaração reafirmou a generalidade e universalidade dos direitos humanos mesmo diante da complexidade cultural, social, política e ideológica reinante à época, o que demonstra a relevância e importância dos direitos humanos no pós-guerra, e a necessidade de uma virada internacional (TRINDADE, 2003).

Mas a humanização da nova ordem internacional não se fundaria apenas em compromissos sem a certeza da efetivação por parte dos Estados. E, nesse sentido, o direito internacional dos direitos humanos com fundamento nos preceitos da Declaração Universal dos Direitos do Homem foi aos poucos criando mecanismos de proteção e efetivação dos direitos humanos, afetando, assim, o núcleo da supremacia dos Estados, fenômeno este que vez e outra surge como entrave à realização plena dos direitos humanos no plano internacional (LÓPEZ, 2004).

Nesse novo contexto global, a preocupação recorrente entre os principais atores da política de defesa, proteção e garantia dos direitos humanos foi a de criar «mecanismos institucionais» capazes de policiar os Estados acerca da observância dos vetores humanísticos da Declaração Universal, de 1948. Assim, paralelamente às ações empreendidas pelas Nações Unidas no plano global, assistiu-se também no plano regional, nomeadamente na Europa e nas Américas, à institucionalização e estruturação de organismos supranacionais destinados à proteção dos direitos humanos, i. e., à Convenção Europeia dos Direitos do Homem, de 1950; e Convenção Americana de Direitos Humanos, de 1969.

Portanto, é nesse contexto que os direitos humanos se afirmam no plano internacional, nomeadamente com a criação de «órgãos jurisdicionais» de proteção, i.e., o «Tribunal Europeu dos Direitos do Homem» e o «Tribunal Interamericano de Direitos Humanos», ambos destinados a garantir a eficácia dos instrumentos jurídicos internacionais de proteção da dignidade humana, que, para além de proteção, também se notabilizam por atribuírem aos 
A CAPACIDADE JURÍDICO-POSTULATÓRIA DO INDIVÍDUO EM ÂMBITO INTERNACIONAL DE PROTEÇÃO E DEFESA DOS DIREITOS HUMANOS

cidadãos do mundo a capacidade postulatória internacional (COMPARATO, 2007), ou seja, a capacidade «jurídico-processual» para demandarem internacionalmente contra os Estados agressores dos Direitos Humanos (TRINDADE, 2003).

Nas linhas seguintes, abordar-se-ão, na opinião deste autor, os dois principais sistemas regionais de proteção e defesa dos direitos humanos, quais sejam, o «europeu» e o «interamericano». A escolha por estes sistemas não é aleatória, pois se funda no «pioneirismo» que lhes são próprios, nomeadamente no que tange ao europeu, cujos instrumentos de coerção por vezes acabam por serem mais eficazes que o interamericano. Contudo, o foco não é avaliar os critérios de eficiência entre os dois sistemas, tampouco traçar um paralelo entre os procedimentos adotados por ambos. A proposta é a de analisar o fenômeno da generalização dos instrumentos de proteção e defesa dos direitos humanos, designadamente a «capacidade jurídico-processual dos indivíduos» nos «órgãos de jurisdição internacional» contemplados pelas Convenções Europeia e Americana de Direitos Humanos.

\section{Convenção Europeia dos Direitos do Homem}

A Convenção Europeia dos Direitos do Homem foi o primeiro tratado internacional celebrado pelos Estados-membros do Conselho da Europa, logo após a Declaração Universal dos Direitos do Homem, de 1948. Foi também o primeiro documento de direito internacional a construir um sistema regional de proteção dos direitos do homem, assim como o primeiro a assegurar o acesso dos particulares às instâncias internacionais, para defesa dos seus direitos contra o respectivo Estado de jurisdição. Segundo afirmação de López, "la Convención se inspire directamente de la Declaración Universal de Derechos Humanos, em su apartado correspondiente a lós derechos civiles y políticos, y del Estatuto del Consejo de Europa, transformando em obligaciones jurídicas precisas vários de lós princípios proclamados em La Declaración Universal y dando concreción a disponsiciones fundamentales em matéria de derecho humanos contenidas en El Estatuto del Consejo de Europa" (LÓPEZ, 2004, p. 85).

Ao longo de seus mais de cinquenta anos, a Convenção Europeia dos Direitos do Homem é hoje o resultado de uma constante evolução jurídica em matéria de proteção e defesa dos direitos humanos. Como afirma Rocha, o modelo europeu representa "um ponto de ruptura no direito internacional clássico, porquanto ultrapassou o estatuto de mera proclamação de direitos constantes da Declaração Universal dos Direitos do Homem" (ROCHA, 20 I 0 , 
p. 18). Ainda segundo Rocha, a "Convenção garante um conjunto de direitos que têm em vista garantir a posição do indivíduo numa comunidade política, ou seja, incidiu a sua atenção sobre direitos cuja estrutura se aproxima dos direitos, liberdades e garantias, deixando de fora os direitos de caráter economico, social e cultural" (ROCHA, 20 I0, p. 24).

Os direitos consagrados na Convenção são indisponíveis, e sua existência enquanto direito dos indivíduos independem da discricionariedade dos Estados. São direitos objetivos que decorrem da ideia de dignidade humana, porque são titulados pelos indíviduos, e não pelos Estados. Em vista disso, se um dos Estados-partes violar na Convenção algum dos direitos convencionados, os demais não podem se eximir ao cumprimento dos deveres a que estão adstritos por força da Convenção. Ou seja, no domínio dos direitos do homem não vale a regra da reciprocidade do direito internacional dos tratados (ROCHA, 20 I0), pois na interpretação dos tratados de direitos humanos prevalece a natureza objetiva das obrigações que consagram (TRINDADE, 2003).

Ademais, tem-se que a Convenção Europeia dos Direitos do Homem não pretendeu ser apenas mero catálogo de direitos, pois sua principal preocupação sempre foi criar mecanismos institucionais capazes de impelir nos Estadospartes a obrigatoriedade de observância dos direitos humanos (ROCHA, 20।0). Ou seja, um sistema de proteção dos direitos do homem não é "credível" se não oferecer aos indivíduos garantias eficazes para defesa dos direitos. É bem como coloca a questão Cançado Trindade, segundo o qual o fenômeno de maior relevância em matéria de direitos humanos é a "coexistência e interação de instrumentos de conteúdo e efeitos jurídicos variáveis", tanto normativos quanto operacionais, a partir dos quais se possam antever resultados positivos no que respeita à observância, defesa e proteção dos direitos do homem (TRINDADE, 2003).

Mas, apesar de a CEDH ter se preocupado em criar um mecanismo institucional que garantisse ao indivíduo a eficácia do direitos humanos, um traço marcante no modelo europeu é o de que a Convenção confere aos Estados a obrigação primeira de preservar e garantir os Direitos Humanos. Conforme dispõe o art. 13 da Convenção, qualquer indívíduo que tiver um direito seu violado à luz da Convenção tem direito a que tal violação seja obstada primeiro pelos órgãos nacionais. No modelo europeu, compete primeiramente aos órgãos internos e ao juiz nacional fazer a primeira avaliação de conformação de um ato estatal ante a Convenção. Buscou-se, dessa forma, a implementação de um sistema coletivo de proteção, em que a competência dos órgãos internacionais é subsidiária e complementar à dos órgãos nacionais. A ideia é 
A CAPACIDADE JURÍDICO-POSTULATÓRIA DO INDIVÍDUO EM ÂMBITO INTERNACIONAL DE PROTEÇÃO E DEFESA DOS DIREITOS HUMANOS

permitir aos Estados, que estão mais próximos dos indivíduos, que façam a primeira interpretação de conformação entre seus atos, a ordem constitucional e a proteção dos direitos humanos consagrada na Convenção, segundo a qual o juiz nacional é como o "peão do sistema institucional europeu de proteção dos direitos do homem, fazendo das instâncias nacionais uma parcela fundamental dos mecanismos de proteção internacional" (ROCHA, 20 I 0, p. 35).

Em suma, para Rocha, "o círculo jurisdicional de proteção dos direitos do homem cria uma complexa interrelação que põe em contacto o direito internacional e o direito interno, os tribunais internacionais e os tribunais nacionais, a qual se revela crucial na garantia dos direitos do homem, tal como garantidos pela Convenção" (ROCHA, 20I0, p. 4I). Contudo, mesmo diante de um amplo círculo de proteção e defesa dos direitos humanos via órgãos nacionais, acontece que pode ainda assim ocorrer violações aos preceitos e valores bases da Convenção. Daí o porquê da criação de um tribunal supranacional, i.e., de um órgão de jurisdição internacional capaz de agir e coibir as violações perpetradas pelos Estados-partes da Convenção, ou seja, de um Tribunal Europeu dos Direitos do Homem.

\section{O Tribunal Europeu dos Direitos do Homem e o reconhecimento da capacidade processual internacional do indivíduo}

O modelo original contemplado na Convenção baseava-se numa tríplice repartição de competências entre a Comissão, o Comitê de Ministros e o Tribunal Europeu dos Direitos do Homem. Esse modelo previa o acesso direto do indivíduo apenas à Comissão, que tinha de realizar o juízo de admissibilidade da queixa e decidia por remeter ou não o caso ao Tribunal. É de se notar, no entanto, que o processo de generalização do direito internacional dos direitos humanos provocou a grande virada do século ocorrida logo após o fim da Segunda Guerra Mundial, virada esta que consistiu basicamente em atribuir ao indivíduo capacidade jurídico-processual de acionar organismos internacionais de proteção dos direitos do homem (TRINDADE, 2003).

Assim, que pese inicialmente a CEDH não prever o acesso direto dos cidadãos ao Tribunal, foram com as alterações introduzidas pelo Protocolo $n^{\circ}$ I I, aberto em Estrasburgo no dia I I de maio de 1994, com vigência a partir de $1{ }^{\circ}$ de novembro de 1998, que definitivamente o indivíduo se afirmou como sujeito dotado de capacidade processual internacional no âmbito europeu. Fundados nos vetores da simplificação processual, concentração de competências e reforço da jurisdicionalização do sistema de controle 
(FERREIRA, 2007), as reformas promovidas pelo $n^{\circ} 11^{\circ}$ foram moldadas basicamente por duas linhas de principais: de um lado o abandono do postulado histórico de que o indivíduo não podia ascender às jurisdições internacionais no mesmo plano do que os Estados soberanos; do outro, a unificação do sistema orgânico com a instalação de um Tribunal permanente (ROCHA, 20 I0).

A consagração da capacidade processual internacional do individuo de acionar o Tribunal Europeu dos Direitos do Homem contra um Estado supostamente violador da Convenção deu-se pelo art. 34, que ao final chega a advertir que não poderá ser criado pelas Altas partes (os Estados!) contratantes qualquer entrave ao exercício desse direito. Mas a par da consagração do indivíduo como sujeito de direito processual internacional, a Convenção procurou também estabelecer limites à legitimação, ou seja, que para ascender ao Tribunal o indivíduo necessariamente tenha de ser «vítima» de um ato contrário à Convenção. Nesse particular, impende salientar que o conceito de vítima não pode se transformar em obstáculo intransponível pela ordem estatal interna, razão por que a jurisprudência do TEDH de há muito vem lapidando e evoluindo nesse sentido, i. e., de que o conceito de vítima de ser interpretado de forma «autônoma» e «independentemente» de conceitos do direito interno, como os de interesse processual, interesse necessidade ou interesse utilidade em participar de um processo legal (TRINDADE, 2003).

Isso implica dizer que só pode se apresentar em juízo quem possuir interesse específico e pessoal, não podendo o indivíduo apresentar ao Tribunal uma questão em abstrato, tal como podem os Estados (ROCHA, 20l0). Para Ferreira, a "legitimidade tem uma configuração subjetiva, isto é, encontra-se amoldada à tutela de posições jurídicas subjetivas, de interesses próprios, não sendo já aceitável a apresentação de uma petição individual tendo por objeto uma ilegalidade abstrata, ao contrário do que pode ocorrer nos domínios dos assuntos interestaduais". (FERREIRA, 2007, p. 905).

Contudo, mais uma vez demonstrando a crescente influência humanizadora do direito internacional, a jurisprudência do TEDH constantemente vem alargando o conceito de vítima, de modo que nenhuma violação à Convenção seja excluída da avalição jurisdicional da Corte, i. e., o Tribunal tem buscado integrar duas realidades: de um lado, admitindo como "vítima" todo aquele que esteja em situação de potencial ou provável risco de lesão provocada por um ato interno desconforme com a Convenção; de outro lado, adotando o conceito de "vítima indireta", que engloba todos aqueles que sofram um prejuízo em razão da violação de um direito de um terceiro", v. g., nos casos de repatriação, em que a esposa e os familiares acabam por serem afetados com o mencionado ato 
A CAPACIDADE JURÍDICO-POSTULATÓRIA DO INDIVÍDUO EM ÂMBITO INTERNACIONAL DE PROTEÇÃO E DEFESA DOS DIREITOS HUMANOS

(ROCHA, 20I0).

Uma das grandes conquistas na afirmação histórica dos direitos humanos é sem dúvida o acesso direto dos indivíduos às instâncias internacionais de proteção e o reconhecimento de sua capacidade processual internacional. Para Cançado Trindade, a contraposição entre as vítimas de violações e os Estados demandados é da própria essência do contencioso internacional dos direitos humanos, porquanto não ser razoável conceder direitos sem atribuir capacidade processual de vindicá-los (TRINDADE, 2003).

Mas o reconhecimento dessa capacidade processual internacional com acesso direto ao Tribunal Europeu dos Direitos do Homem não está livre de questionamentos, como aqueles que apontam para o enfraquecimento do Tribunal, dada a avalanche de petições que tem recebido anualmente desde as alterações promovidas pelo Protocolo $n^{\circ} \mid \mathrm{I}$. É por isso que a Convenção previu alguns requisitos de admissibilidade das petições individuais. $\bigcirc$ mais controvertido desses requisitos e que se pode utilizar como paradigma deste trabalho diz respeito ao esgotamento dos recursos internos.

Essa condição de admissibilidade tem sido o ponto «nevrálgico» da efetividade do sistema de proteção dos direitos humanos instituído pela Convenção Europeia. Para Ferreira, tal condição situa-se no "frágil equilíbrio entre a efetividade da tutela dos direitos humanos em cada situação concreta e a necessidade existencial de assegurar o próprio funcionamento do Tribunal em termos regulares, sem o qual aquela tutela não pode ser assegurada por este órgão jurisdicional" (FERREIRA, 2007, p. 906). Todavia, novamente na esteira humanística, a jurisprudência do Tribunal esclarece que a exigência de esgotamento das vias de recursos internos só se coloca diante dos meios processuais «normamente» disponíveis no país de origem, acessíveis ao individuo e eficazes quanto à reparação das violações alegadas.

Ou seja, o TEDH tem também dispensado a verificação dessa condição quando a utilização dos meios processuais internos disponíveis pode resultar na continuação ou no agravamento da violação dos direitos humanos, tendo em conta os contextos jurídico e político em que os fatos ocorrem. Como leciona Ferreira, o esgotamento dos recursos internos não deve ser entendido em termos automáticos ou absolutos, mas sim mitigado com critério de exigibilidade ou de razoabilidade, e não deve ser conhecido de ofício pelo TEDH; carece, portanto, de invocação e comprovação por parte do Estado demandado (FERREIRA, 2007).

Portanto, de todo o acima exposto, conclui-se que o esgostamento dos recursos internos não pode ser interpretado de forma a se tornar um obstáculo 
instransponível ao acesso dos cidadãos ao Tribunal, o que reforça mais uma vez a prioridade dos direitos humanos ante a atuação dos Estados, daí porque toda interpretação deve ser "pro vitima", tendo em vista a natureza das normas de proteção dos direitos humanos, que visam tutelar a posição dos indivíduos diante dos Estados (ROCHA, 20 I0). Como bem afirma López, nos últimos anos, o Tribunal Europeu dos Direitos Humanos tem contribuído enormemente pela correta aplicação e interpretação dos variados direitos reconhecidos pela Convenção Europeia, traduzindo-se, portanto, em importante guardião dos direitos humanos no espaço europeu (LÓPEZ, 2004).

\section{A Convenção Americana de Direitos Humanos}

A Convenção Americana de Direitos Humanos foi aprovada em 22 de novembro de 1969 e entrou em vigor em 18 de julho de 1978, contando atualmente com 24 Estados-partes. A primeira observação importante a respeito do sistema de proteção dos direitos humanos no continente americano é a sua "geometria variável" (FERREIRA, 2007, p. 9|8), pois a sujeição à jurisdição do Tribunal Interamericano de Direitos Humanos é facultativa, i. e., apesar de integrarem a Convenção Americana de Direitos Humanos, alguns Estados, por opção, não se sujeitam à jurisdição do TIDH, o que na visão de alguns doutrinadores acaba por enfraquecer o sistema interamericano de proteção e defesa dos direitos do homem (FERREIRA, 2007).

Mas não é só a geometria variável que marca o modelo americano. Também o seu formato misto, não totalmente jurisdicionalizado, cuja defesa e proteção dos direitos humanos encontra-se partilhada entre uma Comissão e o Tribunal Interamericano de Direitos Humanos são traços marcantes do modelo idealizado pela $\mathrm{CADH}$, à semelhança do que ocorria no modelo europeu antes das alterações promovidas pelo Protocolo $n^{\circ} \mid \mathrm{I}$.

No modelo interamericano ao indivíduo, não é reconhecida a legitimidade ativa para instaurar um processo no $\mathrm{TIDH}$, pois o direito de petição internacional nos casos de violação aos direitos humanos consagrados pela CADH deve ser exercido na Comissão Interamericana de Direitos Humanos, que é quem tem competência de investigar a veracidade das alegações e ao final emitir juízo de admissibilidade da causa, rementendo-a ao TIDH na hipótese de juízo positivo de admissibilidade da acusão ou denúncia.

No plano, porém, dos poderes e da efetividade da tutela jurisdicional outorgada pelo TIDH, uma vez desencadeada em função da admissibilidade da petição encaminhada pelo indivíduo à Comissão Interamericana de Direitos 
A CAPACIDADE JURÍDICO-POSTULATÓRIA DO INDIVÍDUO EM ÂMBITO INTERNACIONAL DE PROTEÇÃO E DEFESA DOS DIREITOS HUMANOS

Humanos, algumas soluções adotadas na CADH afiguram-se mais avançadas e adequadas do que as constantes da CEDH (FERREIRA, 2007). Conforme será demonstrado nas linhas seguintes, em que pese no sistema interamericano o indivíduo não ter acesso direto à jurisdição do TIDH, o fato é que na prática esta negativa de acesso acaba «neutralizada» pelo amplo acesso que o indivíduo tem perante à Comissão Interamericana, e mesmo no TIDH, nos casos que lhe são submetidos.

\section{A Comissão Interamericana de Direitos Humanos e o direito de petição do cidadão a uma instância supranacional de proteção dos direitos humanos}

Nos termos do art. 4I da CADH, a CIDH tem como função principal promover a observância e a defesa dos direitos humanos, destacando-se, de entre o elenco de competências e funções constantes daquele preceito, as que respeitem às petições e outras comunicações que lhe sejam dirigidas nos termos dos arts. 44 a 5 I da mencionada Convenção. Trata-se de um órgão de duplo caráter orgânico, enquanto órgão da Organização dos Estados Americanos, por um lado, e enquanto órgão da Convenção Americana de Direitos Humanos, por outro.

No que respeita à admissibilidade das petições ou das comunicações dos Estados, os pressupostos exigidos pelo art. 45 da CADH são substancialmente idênticos aos da $\mathrm{CEDH}$, designadamente: a) esgotamento dos meios de reação internos de acordo com os princípios de direito internacional geralmente reconhecidos; b) não decurso de mais de seis meses sobre a prolação da decisão definitiva interna; c) não pendência do assunto objeto da petição ou comunicação noutra instância internacional, nem identidade substancial com outra já apreciada pela CIDH ou ainda por outra instância internacional.

No entanto, assim como ocorre no modelo europeu, também no americano são várias as disposições flexibilizantes dos pressupostos acima enunciados, nomeadamente no que se refere à existência de meios processuais internos efetivos e acessíveis e às condições concretas do caso, que podem tornar inexigível ao indivíduo o esgotamento desses meios ou a obtenção de uma decisão interna definitiva (FERREIRA, 2007).

No que tange ao esgotamento dos recursos internos, a CIDH tem adotado uma diversidade de soluções, que incluem a solicitação de informações adicionais e o adiamento da decisão sobre a admissibilidade das queixas e denúncias, ao invés de simplesmente rejeitá-la (TRINDADE, 2003). Ou seja, a Comissão ao longo da história tem demonstrado constante precaução em 
matérias relacionadas aos direitos humanos, prestigiando quase sempre as medidas que resguardem a integridade dos valores mínimos de dignidade e humanidade.

Também em virtude de uma regra de interpretação firmada na II Conferência Interamericana Extraordinária, realizada no Rio de Janeiro, em 1965, admite-se que o prévio esgotamento dos recursos de direito interno não se aplica em situações de alegada violação generalizada dos direitos humanos. Essa regra de interpretação se aplicou em alguns casos concernentes à suspensão de garantias processuais e outras irregularidades, especialmente em casos ocorridos nos anos 70 (TRINDADE, 2003).

De acordo com o art. 48, n 2 , da Convenção Americana, caso se trate de um caso urgente e sério, a $\mathrm{CIDH}$ pode dar início a um inquérito no território do Estado visado, obtido o prévio consentimento deste, imediatamente após a apresentação de petição ou comunicação em termos formalmente admissíveis. Desse modo, a prática da CIDH tem contribuído para facilitar gradualmente o acesso de presumidas vítimas à instância internacional e a fortalecer sua posição no plano internacional, como legítimos titulares de direitos inalienáveis. Segundo Trindade, de todos os órgãos de supervisão internacional em matéria de direitos humanos, a CIDH tem sido talvez o que mais ampliou o uso de missões de observação in loco, para elaboração de informes sobre violações de direitos humanos (TRINDADE, 2003).

A atuação da CIDH pode ser finalizada por uma das seguintes formas: a) acordo amigável; b) elaboração de Relatório com recomendações ao Estado visado; c) se não forem tomadas as medidas necessárias e recomendadas pela $\mathrm{CIDH}$, desde que o Estado tenha aceitado a jurisdição do TIDH, a Comissão deve submeter o caso àquele órgão jurisdicional, salvo se houve deliberação em contrário; d) relatório em que consigna sua posição e conclusão sobre os fatos envolvendo a causa, fixando novo prazo para que o Estado cumpra as recomendações, procedendo-se, ainda, a inclusão do assunto no Relatório Anual apresentado à Assembleia Geral da OEA.

Portanto, em que pese no sistema interamericano o indivíduo não ter livre acesso à jurisdição do TIDH, essa negativa acaba por ser minimizada pelas inúmeras possibilidades de atuação do particular na Comissão Interamericana de Direitos Humanos. Ademais, a atuação preliminar da Comissão na fase de admissibilidade das queixas individuais tem se mostrado das mais importantes, nomeadamente por conta de sua atuação mediante inquéritos e visitas localizadas, o que só vem contribuir para com os julgamentos dos casos submetidos ao Tribunal Interamericano de Direitos Humanos. E sendo assim, 
A CAPACIDADE JURÍDICO-POSTULATÓRIA DO INDIVÍDUO EM ÂMBITO INTERNACIONAL DE PROTEÇÃO E DEFESA DOS DIREITOS HUMANOS

dúvidas não pairam de que também no sistema interamericano o indíviduo tem a sua capacidade postulatória internacional garantida, ou seja, de que mesmo diante da inércia dos órgãos nacionais a pessoa possa se valer da jurisdição internacional para proteção dos direitos que lhes são inerentes.

\section{O Tribunal Interamericano de Direitos Humanos}

O primeiro regulamento do TIDH (1980) se inspirou no Regulamento então vigente no TEDH, o qual, por sua vez, tomou como modelo o Regulamento da Corte Internacional de Justiça (CIJ) (TRINDADE, 2003). O $\mathrm{TIDH}$ apenas conhece dos casos que lhe são submetidos pela CIDH ou pelos Estados aderentes à CADH que não tenha negado a competência jurisdicional do Tribunal em matérias que digam respeito às violações aos direitos humanos.

A CADH não reconhece aos particulares o direito de acesso direto ao TIDH, embora essa deficiência seja de alguma forma mitigada com a audição dos particulares pela CIDH e pela circunstância de o art. 23 do Reg. TIDH permitir que, uma vez admitido o caso TIDH, aqueles possam intervir de forma autônoma no desenrolar do processo, apresentando requerimentos, alegações e prova, por si ou pelos seus representantes.

Outro detalhe importante que traduz a importância de participação do indivíduo no processo de proteção e defesa dos direitos do homem, nomeadamente no sistema interamericano, diz respeito à possibilidade de que na etapa de reparações os representantes legais das vítimas ou de seus familiares apresentem seus próprios argumentos e provas perante a Corte de "forma autônoma", sem a intermediação da Comissão Interamericana de Direitos Humanos. Conforme afirma Trindade, este passo significativo abre caminho para novos desenvolvimentos rumo ao reconhecimento futuro do locus standi dos indivíduos em todas as etapas do procedimento ante a Corte Interamericana (TRINDADE, 2003). Portanto, como afirma Trindade, o fortalecimento da capacidade processual dos indivíduos no sistema interamericano tem se verificado gradualmente de diferentes formas, seja nas funções contenciosas quanto consultivas do Tribunal Interamericano de Direitos Humanos.

No que tange especificamente às medidas provisórias, destinadas a medidas urgentes e tendentes à proteção imediata de direitos contemplados na Convenção, o TIDH já chegou a receber petição direta de um cidadão violado. No caso, tratou-se de um fato noTribunal Constitucional (2000), em que uma peticionária (magistrada), destituída do Tribunal Constitucional do Perú, 
submeteu diretamente ao TIDH uma solicitação de medida provisória para sanar o ato violador, qual seja, seu irregular afastamento das funções que exercia no Poder Judiciário Peruano. Sendo um caso pedente no Tribunal, e não se encontrando em sessão ordinária, o presidente da Corte, pela primeira vez na história, adotou de ofício uma medida urgente, que culminou na Resolução de 7 de abril de 2000, dada a extrema gravidade e urgência, e para evitar danos irreparáveis à peticionária'.

Destarte, como acima demonstrado, apesar de o indivíduo não ter acesso direto ao Tribunal Interamericano de Direitos Humanos, a mencionada instância jurisdicional internacional não the tem fechado as portas diante de graves violações aos direitos humanos. Mesmo tendo a Comissão Interamericana o papel fundamental de investigar e submeter (ou não) ao TIDH os casos que the são apresentados, o Tribunal tem reconhecido a proeminência dos direitos humanos, razão por que, em casos excepcionais, tem admitido conhecer de petições individuais sem a intervenção prévia da $\mathrm{CIDH}$, o que mais uma vez denota a importância de se reconhecer ao indivíduo o direito de petição a uma instância supranacional.

\section{CONCLUSÃO}

Superados os capítulos antecedentes, chegou-se finalmente à conclusão do trabalho, local dos mais apropriados para reunir os resultados obtidos ao longo dessa investigação. Relembre-se, contudo, a não pretensão de se esgotarem todas as questões circunscritas ao tema em questão. Dessa forma, sem descartar as várias conclusões apresentadas ao longo do trabalho, abaixo seguem as que se entende de maior relevância:

a) Os sistemas de proteção dos direitos humanos em âmbito global e regional são essencialmente complementares, e nas últimas décadas tem-se observado gradual expansão da proteção internacional dos direitos humanos e a correspondente consolidação dos sistemas de proteção, claramente orientados a salvaguardar as vítimas de violações dos direitos humanos;

'Caso Tribunal Constitucional vs. Peru, 2001. Disponível em: http://www.corteidh.or.cr/docs/casos/articulos/seriec_7l_esp.pdf. Acesso em 8 de julho de 2012. 
b) $\bigcirc$ modelo europeu contempla um sistema de proteção essencialmente jurisdicional, que abrange obrigatoriamente todos os Estados aderentes à Convenção Europeia de Direitos Humanos, cuja marca principal é a de reconhecer expressamente ao indivíduo a legitimidade ativa para ascender diretamente à jurisdição supranacional, ou seja, ao Tribunal Europeu de Direitos Humanos.

c) O sistema interamericano é marcado pela distribuição de competências entre uma Comissão e o Tribunal, a exemplo do que ocorria no sistema europeu anteriormente ao Protocolo de $n^{\circ}$ I I. Nesse sistema, o indivíduo não tem acesso direto ao TIDH, contudo, mesmo diante da negativa de livre acesso do indivíduo à jurisdição do Tribunal, tanto a atuação da Comissão quanto a jurisprudência do TIDH têm caminhado no sentido de reconhecer o direito de petição ao indivíduo, seja perante a Comissão ou ao Tribunal.

d) A progressiva evolução dos instrumentos normativos internacionais, aliada à crescente jurisdicionalização dos direitos humanos em âmbito global tem perfilhado a máxima de que se deve reconhecer ao indivíduo a capacidade de postular nos órgãos supranacionais as medidas necessárias à salvaguarda dos princípios e valores inerentes à dignidade humana;

e) Ao menos no que tange a questões afetas aos direitos humanos, não pairam dúvidas de que o indivíduo logrou posicionar na cena global como sujeito internacional de direitos inalienáveis, razão por que, diante de graves violações aos direitos humanos, sempre poderá socorrer-se às instâncias supranacionais, tal como ocorre no modelo europeu e interamericano de direitos humanos.

\section{REFERÊNCIAS}

BARRETO, Irineu Cabral. A Convenção Europeia dos Direitos do Homem. Anotada. Coimbra: Coimbra, 2005.

BÍBLIA. Bíblia do estudante de aplicação pessoal. Brasilia: Sociedade Bíblica do Brasil, 1995.

BOTELHO, Catarina Santos. A tutela directa dos direitos fundamentais. Avanços e recuos na dinâmica garantística das justiças constitucional, administrativa e internacional. Coimbra: Almedina, 20 I 0.

COMPARATO, Fábio Konder. A afirmação histórica dos direitos humanos. São Paulo: Saraiva, 2007. 
Convenção Americana de Direitos Humanos, 1969. Disponível em: http://www.amb.com.br/fonavid/Legislacao_Pacto_San_Jose_da_Costa_Rica_ __1969[I].pdf. (acesso em 2 de Junho de 20 I2).

Convenção Europeia dos Direitos do Homem, 1950. http://www.echr.coe.int/NR/rdonlyres/75 I 0566B-AE54-44B9-AI639| 2EF I 2B8BA4/0/POR_CONV.pdf. (acesso em 2 de Junho de 20 I 2).

Declaração Americana dos Direitos e Deveres do Homem, 1948. Disponível em: http://pfdc.pgr.mpf.gov.br/atuacao-e-conteudos-deapoio/legislacao/direitos-humanos/declar_dir_dev_homem.pdf. (acesso em 2 de Junho de 20/2).

Declaração de Direitos do Bom Povo de Virgínia, 1776. http://www.rolim.com.br/2002/_pdfs/06II.pdf. (acesso em 7 de Junho de 2012).

Declaração Universal dos Direitos do Homem e do Cidadão, 1789. Disponível em: http://pfdc.pgr.mpf.gov.br/atuacao-e-conteudos-deapoio/legislacao/direitos-humanos/declar_dir_homem_cidadao.pdf. (acesso em 18 de Março de 20 I2).

Declaração Universal dos Direitos do Homem, 1948. Disponível em: http://www.fpce.up.pt/sae/pdfs/Decl_Univ_Direitos_Homem.pdf. (acesso em 2012 de Julho de 8$)$.

FERREIRA, Rui Cardona. Os sistemas de protecção jurisdicional dos direitos do humanos na Convenção Europeia dos Direitos do Homem e na Convenção Americana de Direitos Humanos. O Direito, 139, IV, 2007: 895-932.

HAARSCHER, Guy. A filosofia dos direitos do homem. Lisboa: PIAGET, 1993.

IDA, Ryuichi. Bioética e futuro dos seres vivos. In: BINDÉ, Jérôme. Para onde vão os valores? Lisboa: Piaget, 2006, 297-303.

JUSTO, A. Santos. Nótulas de histórica do pensamento jurídico. Coimbra: Coimbra, 2005.

LÓPEZ, Mikel Berraondo. Los derechos humanos en la globalización. Bilbao: Universida de Deusto, 2006. 
MIRANDA, Jorge. Curso de Direito Internacional Público. Parede: Principia, 2012.

MONTESQUIEU, Charles-Louis de Secondatt. O Espírito das Leis. São Paulo: Martins Fontes, 1996.

ORAÁ, Jaime. La Declaración Universal de Derechos Humanos. La Protección internacional de los derechos humanos en los albores del siglo XXI. (Director) Felipe Gómez Isa. Bilbao: Universidade de Deusto, 2003.

Organização dos Estados Americanos. Disponível em: http://www.oas.org/pt/. (acesso em 2012 de Junho de 2).

ROCHA, Armando. O contencioso dos direitos do homem no espaço europeu. Lisboa: Universidade Católica, 2010.

SANTOS, Boaventura de Souza. Os direitos humanos na sociedade pósmodernidade. Oficina do CES. Universidade de Coimbra. Estudo Geral. Junho de 1989. Disponível em: http://hdl.handle.net/I03 I6/I0919. (acesso em 17 de Março de 20 I2).

Tribunal Interamericano de Direitos Humanos: Caso Tribunal Constitucional vs. Perú, $\quad 2001$. Disponível e m: http://www.corteidh.or.cr/docs/casos/articulos/seriec_7l_esp.pdf. (acesso em 2012 de Julho de 8$)$.

TRINDADE, Antônio Augusto Cançado. El sistema interamericano de protección de los derechos humanos (1948-2008). In: GÓMEZ ISA, Jo'se Manuel Pureza. La protección internacional de los derechos humanos en los albores del siglo XXI. Bilbao: Universidad de Deusto, 2003, 549-59l.

—. O direito internacional em um mundo em transformação (Ensaios, 1976200 I). Rio de Janeiro: Renovar, 2002.

—. Tratado de Direito Internacional dos Direitos Humanos, Vol. I. Porto Alegre: Sergio Antonio Fabris Editor, 2003. 
—. Tratado de Direito Internacional dos Direitos Humanos, Vol. III. Porto Alegre: Sergio Antonio Fabris Editor, 2003.

WARBURTON, Nigel. Elementos básicos de filosofia. Lisboa: Gradiva, 2007.

Recebido em: 01/10/2014 Aprovado em: 06/08/2015 